\title{
Is the sharp increasing trend of multiple sclerosis incidence real in Iran?
}

\author{
Ali Hosseinzadeh ${ }^{1 *}$ D, Behnaz Sedighi ${ }^{2}$, Jamshid Kermanchi ${ }^{3}$, Mohammad Heidari $^{4}$ and Ali Akbar Haghdoost ${ }^{5}$
}

\begin{abstract}
Background: Some epidemiologic studies have reported a sharp increase in multiple sclerosis (MS) incidence in different provinces in Iran. This report aimed to investigate more closely the increasing trend of MS incidence in the past 10 years in Iran.

Methods: In this longitudinal study, the data for all MS patients meeting the McDonald criteria were obtained from a national registry, coordinated by the Ministry of Health (MOH). Joinpoint (JP) regression was used for time trend analysis of MS incidence and determine the optimal number of significant joinpoints. Finally, an annual percentage change (APC) in MS incidence for each segment of the trend line was estimated with 95\% confidence interval.

Results: The mean age of the patients and the mean annual incidence rate of MS were 30.9 \pm 1.1 and $5.3 \pm 1.9$ per 100,000 population, respectively. The overall incidence rate of MS had increased significantly from 2.14 in 2006 to its peak (7.5) in 2014, per 100,000 population (APC $=12 \%, P<0.001$ ). The first JP was observed in 2011 in both male and female groups. The overall APC in the first segment was $22.6 \%(17.2-28.2 \%, p<0.01)$. Besides, the corresponding APC values for males and females were $22.1 \%(14.7-30 \%, p<0.01)$ and $22.5 \%(17.5-27.8 \%, p<0.01)$, respectively. After 2011, the MS incidence underwent a more or less decreasing trend in both genders.

Conclusion: Contrary to previous studies, the MS incidence trend in Iran was rising just before 2011, and in the recent decade, Iran has a stable rate of MS cases.
\end{abstract}

Keywords: Multiple sclerosis, Autoimmune diseases, Incidence, Increasing, Joinpoint regression

\section{Background}

Multiple sclerosis (MS) is a central nervous system disease with unknown etiology which usually manifests in the third or fourth decades of life [1]. Evidence has revealed an increasing trend in the incidence and prevalence of MS in recent decades worldwide [2-4]. Likewise, several studies have reported a sharp increase in MS incidence in different provinces of Iran. However, it is unclear whether this upward trend is due to improvement in case ascertainment or increased incidence of MS. [5-8] Iran is the second-largest country in the Middle East with a large young population. The country has experienced significant

* Correspondence: a.hossein20@yahoo.com

1 Department of Epidemiology, School of Public Health, Shahroud University of Medical Sciences, Shahroud, Iran

Full list of author information is available at the end of the article industrial and technological growth in recent decades [9]. Therefore, most of the studies conducted in Iran have attributed the increasing trend in MS incidence to environmental factors and lifestyle changes as a result the rising trend of industrialization and urbanization in the country $[5-8,10,11]$. However, some factors may lead to a false increase in MS incidence including better and faster diagnosis, availability of paraclinical and MRI tests, increased number of neurologists, increased public awareness and information, improvement of the disease registration system, and changing diagnostic criteria. Previous studies have paid less attention to the above-mentioned factors, while these factors appear to play an essential role in the increasing trend of MS in Iran. Considering this gap in the literature, this study aimed to investigate more closely the 
increasing trend of MS incidence in the past 10 years in Iran.

\section{Methods}

To answer the research question, we used the data published via the Iranian monitoring and treatment surveillance system for MS patients from 2006 to 2016. Because the Iranian government pays a considerable amount of treatment costs for MS patients, there is a population-based computerized registry in each province to register MS patients. Also, as patients have access to neurologists in almost all parts of Iran [12], it seems that nearly all MS patients have been registered in this registry system. In this study, the 2000-2025 WHO population was used as a standard population to remove the effect of different population age structures in different years.

For time trend analysis, we used Joinpoint software, which is appropriate for studying the changes in diseases with a low incidence rate. Unlike linear models, joinpoint regression breaks down the whole trend into different segments with positive and negative slopes of the changes. In each segment, the software fits the best line to the incidence points and annual percentage change calculated for each segment as an average rate of the change in that span of time. For this purpose, in the first step, it fits the simplest model to the data, and the analysis starts with the least number of joinpoints. Then, it checks whether more joinpoints could be fitted to the data. We chose the Monte Carlo permutation test to select the optimal number of statistically significant joinpoints. Finally, an annual percentage change (APC) in MS incidence for each segment of the trend line was estimated with $95 \%$ confidence interval. In the present study, the mean annual sex-specific prevalence rates were computed considering all patients to be alive with definite MS in the study period. We described the epidemiological characteristics of MS cases for different segments of the trends.

\section{Results}

A total of 44,894 newly diagnosed cases (34,729 females [77.4\%]) were registered in the MS registry system of MOH from March 21, 2006, to March 20, 2016. The average female-to-male ratio of the MS incidence was 3.4. The mean age of the patients was $30.9 \pm 1.1$ years at the time of diagnosis $(30.5 \pm 1.1$ years in females and $31.6 \pm 1.2$ years in males). The mean annual MS incidence rate was $5.3 \pm 1.9$ per 100,000 population $(8.5 \pm$ 2.9 and $2.4 \pm 0.9$ in females and males, respectively).

The overall MS incidence had increased significantly from 2.2 (95\% CI: $2.0-2.3$ ) in 2006 to 6.7 (95\% CI: 6.56.7 in 2016 , per 100,000 population, with its peak 7.5 (95\% CI: 7.2-7.6) in 2014 ( $\mathrm{APC}=12 \%, P<0.001)$. The trend of MS incidence and APC in different age groups has been shown in Table 1.

The first joinpoint has occurred in 2011 in both genders. Figure 1 shows the APC in MS incidence before and after 2011. The overall APC in the first period (before 2011$)$ was $22.6 \%(17.2-28.2 \%, p<0.01)$. It was $22.1 \%(14.7-30 \%, p<0.01)$ and $22.5 \%(17.5-27.8 \%, p<$ 0.01 ) in males and females, respectively. After 2011 (the second period), the trend of MS incidence was more or less decreasing. Accordingly, the APC of MS incidence was $-1.6 \%(-9.5-6.9 \%)$ overall, $0.2 \%(-10.9-12.7 \%)$ in males, and $-2.0 \%(-9.4-6.0 \%)$ in females (Fig. 1).

Table 2 shows epidemiological features for two periods (before and after 2011) separately. The mean annual MS incidence and prevalence were $3.9 \pm 1.6$ and $32.7 \pm 17.8$ in the first period, $7.0 \pm 0.3$, and $62.5 \pm 38.2$ in the second period respectively.

\section{Discussion}

Our study revealed that MS incidence increased significantly from 2.2 in 2006 to 6.7 in 2016, per 100,000 population. Our findings are in line with previous studies and show a similar trend in the same period in Iran $[6,7,13]$. According to Elhami et al. [6], the MS incidence in Tehran province has increased from 0.68/ 100000 in 1989 to $2.93 / 100000$ in 2008. Furthermore, Etemadifar et al. [7] showed that the MS incidence in Isfahan province has increased from 3.64/100000 in 2006 to $9.1 / 100000$ in 2009. Similarly, Izadi et al. [13] have reported that the MS incidence rate in Fars province had risen from 4.1/100000 in 2002 to 8.98/100000 in 2012.

In recent years, Iran has experienced significant growth in the field of medicine and access to health services. Because of such a development in the surveillance system, patients, even in deprived areas, have access to neurologists and health services through the referral system [12]. Therefore, the increase in MS incidence in Iran, especially in more developed provinces, might be the result of improved and modified diagnosis criteria (the availability of magnetic resonance imaging (MRI) and paraclinical tests), public awareness of the disease and its therapies, and improvement and the completeness of the registration system in recent years [14].

As shown in Fig. 1, the trend of MS incidence in Iran is marked by two distinct periods (i.e. the first period from 2006 to 2011 and the second period from 2012 to 2016). Although the MS incidence in the second period is high, the slope of MS incidence in the first period is higher. One of the factors that may have caused a different trend slope in the MS incidence in these two periods is the improvement of the disease registration system in the recent decade. The registration of MS patients in Iran began in $2005[9,15]$. To the best of our knowledge, 
Table 1 Age standardized rate of multiple sclerosis Incidence in Iran during 2006-2016 (Per100000 Persons) in different age groups in both genders

\begin{tabular}{|c|c|c|c|c|c|c|c|c|c|c|c|c|c|c|}
\hline Age groups & $\begin{array}{l}\text { Years } \\
\text { Genders }\end{array}$ & 2006 & 2007 & 2008 & 2009 & 2010 & 2011 & 2012 & 2013 & 2014 & 2015 & 2016 & $\mathrm{APC}^{\mathrm{a}}$ & $P$-value \\
\hline \multirow[t]{3}{*}{$<19$} & Males & 0.21 & 0.33 & 0.41 & 0.47 & 0.53 & 0.55 & 0.66 & 0.61 & 0.50 & 0.55 & 0.44 & 7.7 & 0.01 \\
\hline & Females & 1.06 & 1.28 & 1.32 & 1.82 & 1.98 & 2.54 & 2.49 & 2.42 & 2.36 & 1.96 & 1.71 & 5.2 & 0.01 \\
\hline & Total & 0.63 & 0.75 & 0.78 & 1.01 & 1.09 & 1.53 & 1.56 & 1.51 & 1.43 & 1.26 & 1.02 & 6.0 & 0.01 \\
\hline \multirow[t]{3}{*}{ 20-29 } & Males & 1.74 & 2.39 & 2.34 & 3.09 & 3.95 & 4.66 & 5.57 & 5.95 & 6.55 & 6.31 & 5.37 & 12.2 & 0.01 \\
\hline & Females & 6.86 & 8.39 & 90.3 & 11.16 & 18.12 & 18.67 & 22.19 & 22.33 & 23.83 & 20.61 & 19.78 & 6.1 & 0.4 \\
\hline & Total & 4.28 & 5.37 & 5.65 & 7.10 & 9.30 & 11.66 & 12.50 & 12.07 & 12.53 & 10.85 & 9.90 & 9.3 & 0.01 \\
\hline \multirow[t]{3}{*}{ 30-39 } & Males & 1.79 & 3.14 & 2.68 & 3.14 & 4.05 & 5.62 & 5.85 & 5.51 & 6.66 & 6.49 & 5.93 & 12.0 & 0.01 \\
\hline & Females & 6.83 & 11.20 & 11.78 & 14.66 & 19.54 & 21.22 & 21.25 & 20.79 & 21.77 & 21.56 & 20.85 & 11.3 & 0.01 \\
\hline & Total & 4.26 & 6.75 & 6.61 & 8.06 & 10.68 & 13.31 & 15.11 & 15.47 & 17.17 & 17.16 & 16.58 & 13.9 & 0.01 \\
\hline \multirow[t]{3}{*}{ 40-49 } & Males & 1.08 & 2.05 & 1.63 & 1.98 & 2.62 & 4.10 & 4.07 & 4.11 & 4.33 & 4.44 & 4.33 & 13.7 & 0.01 \\
\hline & Females & 3.42 & 5.72 & 5.93 & 7.80 & 10.48 & 12.16 & 12.41 & 13.60 & 13.82 & 13.05 & 13.52 & 13.6 & 0.01 \\
\hline & Total & 2.23 & 3.72 & 3.53 & 4.54 & 6.09 & 8.09 & 8.72 & 9.58 & 9.87 & 9.48 & 9.63 & 14.8 & 0.01 \\
\hline \multirow[t]{3}{*}{ 50-59 } & Males & 0.39 & 0.41 & 0.21 & 0.73 & 0.62 & 1.16 & 1.45 & 1.20 & 1.79 & 1.74 & 2.03 & 22.5 & 0.01 \\
\hline & Females & 0.86 & 1.65 & 1.39 & 2.29 & 3.36 & 3.02 & 2.40 & 3.43 & 3.62 & 3.97 & 4.63 & 14.9 & 0.01 \\
\hline & Total & 0.62 & 0.94 & 0.67 & 1.33 & 1.66 & 2.09 & 2.07 & 2.55 & 3.00 & 3.16 & 3.67 & 19.7 & 0.01 \\
\hline \multirow[t]{3}{*}{$>60$} & Males & - & 0.04 & 0.07 & 0.13 & 0.07 & 0.17 & 0.06 & 0.20 & 0.28 & 0.36 & 0.25 & 31.1 & 0.01 \\
\hline & Females & 0.08 & 0.30 & 0.04 & 0.34 & 0.54 & 0.44 & 0.23 & 0.36 & 0.57 & 0.40 & 0.48 & 17.1 & 0.01 \\
\hline & Total & 0.04 & 0.15 & 0.06 & 0.23 & 0.28 & 0.31 & 0.16 & 0.31 & 0.48 & 0.43 & 0.41 & 22.3 & 0.01 \\
\hline
\end{tabular}

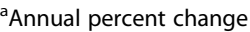

the MS registration system in Iran was not very accurate in the early years, and many patients and physicians were not aware of such a registration system. Therefore, it seems that many patients with MS had not been registered in the first years, but as time passed, the unregistered patients in the years before 2006 were gradually identified and registered in subsequent years and produced a sharp slope in the MS incidence in the first few years. The registration system has not improved in all provinces of Iran at the same time, and it developed differently across the provinces.
Also, to the best of our knowledge, the most crucial factor that may explain the increase of MS incidence rate in the second period (2012-2016) compared to the first period (2006-2011) is the change of MS diagnostic criteria in Iran in 2011. Until 2011, the McDonald's criterion was used to diagnose MS patients In Iran $[15,16]$. According to this criterion, those with 9 MS plaques in the brain are diagnosed as having MS. Changes were made to the McDonald's criterion in 2011 and for the diagnosis of MS, 3 MS plaques were considered sufficient in the brain [16]. Therefore, this issue increased
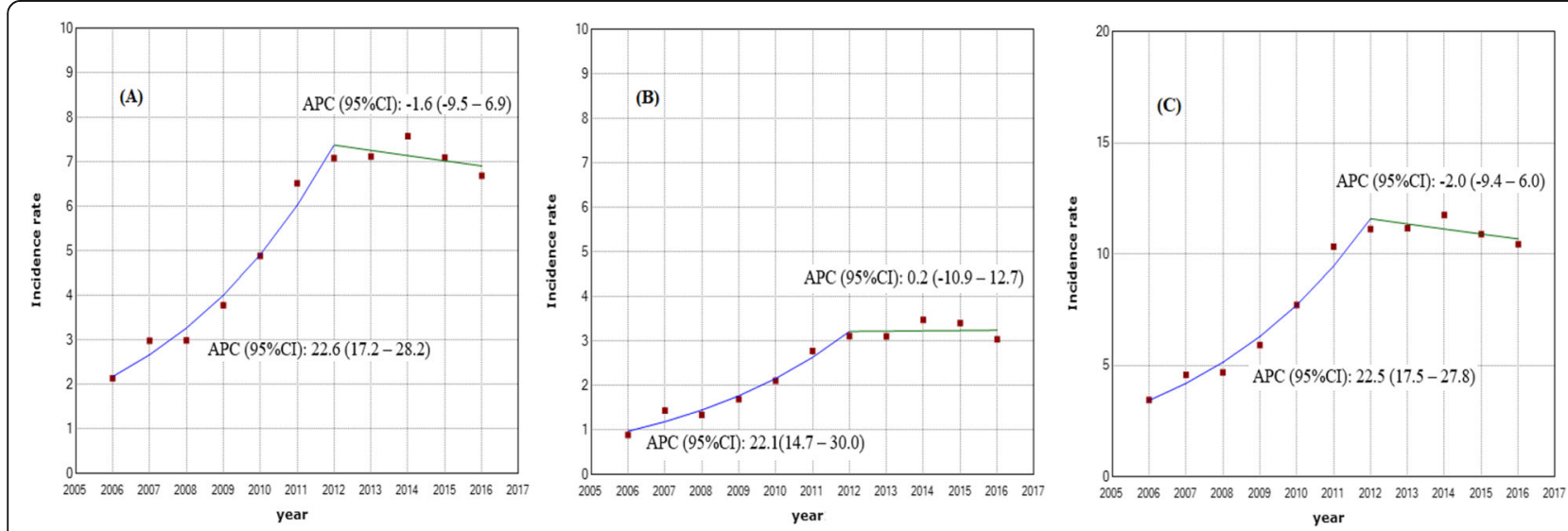

Fig. 1 MS incidence trend over the 2006-2016 period in (a) Overall (b) Males (c) Females 
Table 2 Epidemiological characteristics of MS in the 2006-2011 and 2012-2016 periods

\begin{tabular}{|c|c|c|c|c|c|c|}
\hline & \multicolumn{6}{|l|}{ Study period } \\
\hline & \multicolumn{3}{|l|}{ 2006-2011 } & \multicolumn{3}{|l|}{ 2012-2016 } \\
\hline & Total & Males & Females & Total & Males & Females \\
\hline Mean age of patients at the diagnosis time & $30.15 \pm 0.62$ & $30.79 \pm 0.74$ & $29.97 \pm 0.61$ & $31.91 \pm 0.73$ & $32.63 \pm 0.72$ & $31.69 \pm 0.73$ \\
\hline Mean new cases of MS & $2861 \pm 1235$ & $635 \pm 258$ & $2226 \pm 978$ & $5546 \pm 218$ & $1271 \pm 84$ & $4275 \pm 160$ \\
\hline Mean annual MS incidence & $3.90 \pm 1.58$ & $1.70 \pm 0.66$ & $6.51 \pm 2.58$ & $7.01 \pm 0.27$ & $3.18 \pm 0.19$ & $10.96 \pm 0.42$ \\
\hline Mean annual MS prevalence & $32.75 \pm 17.85$ & $14.54 \pm 7.48$ & $51.46 \pm 29.05$ & $62.56 \pm 38.26$ & $28.27 \pm 16.06$ & $97.82 \pm 61.58$ \\
\hline
\end{tabular}

the sensitivity of this criterion for the diagnosis of MS and led to the early diagnosis of patients with MS. As a result, it could affect the MS incidence and prevalence in recent years and should be reconsidered. Another point to be considered in examining the trend of MS in Iran is the delay time from the onset of disease to the diagnosis. The mean diagnostic delay of MS was about 9 months after 2011. Therefore, the decreasing trend observed after 2011 does not seem to be due to diagnostic delay.

Another point is the precision and accuracy of the analytical methods. In this study, we used the developed software for the first time to test the changes in MS trends in Iran, which allows the data to have nonlinear changes. It is noteworthy that the joinpoint regression model is mostly used for cancer studies, although it may well be adequate for other diseases including MS. [17]

Finally, it should be pointed out that some reports have shown that the use of MRI to diagnose MS in Iran has increased considerably in recent years $[14,18]$. Therefore, an increase in the incidence of MS is more likely to be due to improvement in case ascertainment than to increasing incidence, especially in more developed provinces.

\section{Conclusion}

Contrary to previous studies, the MS trend in Iran is rising just before 2011, and in recent years, Iran has experienced a stable rate of MS cases.

\section{Abbreviations}

MS: Multiple sclerosis; MOH: Ministry of Health; JP: Joinpoint; APC: Annual percent change; MRI: Magnetic resonance imaging

\section{Acknowledgements}

Not applicable.

\section{Authors' contributions}

Data analysis and interpretation were performed by $\mathrm{AH}$ and $\mathrm{MH}$. $\mathrm{AH}$ wrote the first draft of the manuscript and was then critically revised by $A A H, B S$, $\mathrm{JK}$, and $\mathrm{MH}$. All authors read and approved the final version of the manuscript, and agree to be accountable for all aspects of the work.

\section{Funding}

Not applicable.

\section{Availability of data and materials}

The datasets used during the current study are available from the corresponding author on reasonable request.
Ethics approval and consent to participate

The data was obtained from the $\mathrm{MOH}$ without any personal ID for this secondary analysis. The study protocol was approved by the institutional review boards (IRB) at the ethics committee of Kerman University of Medical Sciences (IR.KMU.REC.1397.011). It has to be mentioned that the data of registries in Iran has been collected from subjects based on the national ethical codes. Therefore, according to the above-mentioned IRB protocol and based on the national regulations, there is no need for consent. In this study, administrative permissions to access the raw data had been obtained from the National MS committee in $\mathrm{MOH}$.

\section{Consent for publication}

Not applicable.

\section{Competing interests}

There are no conflicts of interest.

\section{Author details}

${ }^{1}$ Department of Epidemiology, School of Public Health, Shahroud University of Medical Sciences, Shahroud, Iran. ${ }^{2}$ Neurology Research Center, Kerman University of Medical Science, Kerman, Iran. ${ }^{3}$ Deputy of Curative Affairs, Ministry of Health and Medical Education (MOHME, Tehran, Iran. ${ }^{4}$ Clinical Research Development Unit of Imam Khomeini Hospital, Urmia University of Medical Sciences, Urmia, Iran. ${ }^{5}$ HIV/STI Surveillance Research Center, and WHO Collaborating Center for HIV Surveillance, Institute for Futures Studies in Health, Kerman University of Medical Sciences, Kerman, Iran.

Received: 10 May 2020 Accepted: 18 December 2020

Published online: 07 January 2021

\section{References}

1. Poorolajal J, Mazdeh M, Saatchi M, Ghane ET, Biderafsh A, Lotfi B, et al. Multiple sclerosis associated risk factors: a case-control study. Iran J Public Health. 2015;44(11):1498.

2. Pugliatti $M$, Rosati $G$, Carton $H$, Riise $T$, Drulovic J, Vécsei $L$, et al. The epidemiology of multiple sclerosis in Europe. Eur J Neurol. 2006;13(7):700-22.

3. Houzen H, Niino M, Hirotani M, Fukazawa T, Kikuchi S, Tanaka K, et al. Increased prevalence, incidence, and female predominance of multiple sclerosis in northern Japan. J Neurol Sci. 2012;323(1-2):117-22.

4. Modrego PJ, Pina MA. Trends in prevalence and incidence of multiple sclerosis in Bajo Aragon, Spain. J Neurol Sci. 2003;216(1):89-93.

5. Sahraian MA, Sahebkar M, Dehghani R, Derakhshan-Jazari M, KazamiMoghaddam V, Kouchaki E. Multiple sclerosis-a disease on a dramatically rising trend in Iran: review of possible reasons. Iranian J Neurol. 2017;16(1): 34-40.

6. Elhami S-R, Mohammad K, Sahraian MA, Eftekhar H. A 20-year incidence trend (1989-2008) and point prevalence (march 20, 2009) of multiple sclerosis in Tehran, Iran: a population-based study. Neuroepidemiology. 2011;36(3):141-7.

7. Etemadifar M, Maghzi A-H. Sharp increase in the incidence and prevalence of multiple sclerosis in Isfahan, Iran. Mult Scler J. 2011;17(8):1022-7.

8. Mousavizadeh A, Dastoorpoor M, Naimi E, Dohrabpour K. Time-trend analysis and developing a forecasting model for the prevalence of multiple sclerosis in Kohgiluyeh and Boyer-Ahmad Province, southwest of Iran. Public Health. 2018;154:14-23.

9. Hosseinzadeh A, Baneshi M, Sedighi B, Kermanchi J, Haghdoost A-A. Incidence of multiple sclerosis in Iran: a nationwide, population-based study. Public Health. 2019;175:138-44. 
10. Maghzi A, Ghazavi H, Ahsan M, Etemadifar M, Mousavi S, Khorvash F, et al. Increasing female preponderance of multiple sclerosis in Isfahan, Iran: a population-based study. Mult Scler J. 2010;16(3):359-61.

11. Hosseinzadeh A, Baneshi MR, Sedighi B, Kermanchi J, Haghdoost AA.

Geographic variations of multiple sclerosis in Iran: a population based study. Multiple Sclerosis Relat Disord. 2019;28:244-9.

12. Noori Hekmat S, Hashemi H, Haghdoost A, Haji Aghajani M, Janbabaee G, Maher A, et al. Specialized and geographic distribution of specialists in Iran in 2016 and its estimates in 2026. Iran J Epidemiol. 2018;13(13):122-32.

13. Izadi S, Nikseresht AR, Poursadeghfard M, Borhanihaghighi A, Heydari ST. Prevalence and incidence of multiple sclerosis in Fars province, southern Iran. Iranian J Med Sci. 2015;40(5):390.

14. Almasi-Hashiani A, Sahraian MA, Eskandarieh S. Evidence of an increased prevalence of multiple sclerosis: a population-based study of Tehran registry during 1999-2018. BMC Neurol. 2020;20:1-7.

15. Hashemilar M, Savadi Ouskui D, Farhoudi M, Ayromlou H, Asadollahi A. Multiple sclerosis in East-Azerbaijan, north West Iran. Neurol Asia. 2011;16(2): $127-31$.

16. Polman $\mathrm{CH}$, Reingold SC, Banwell B, Clanet M, Cohen JA, Filippi M, et al. Diagnostic criteria for multiple sclerosis: 2010 revisions to the McDonald criteria. Ann Neurol. 2011;69(2):292-302.

17. Daiana B, Lucia K, Francesco G, Andrea M, Lucia G, Giorgia S, et al. Mortality trend for multiple sclerosis in Italy during the period 1980-2015. Multiple Sclerosis and Related Disorders. 2020;44:102240.

18. Mohebi F, Eskandarieh S, Mansournia MA, Mohajer B, Sahraian MA. Multiple sclerosis in Tehran: rising prevalence alongside stabilizing incidence-true increase or enhanced diagnosis? Arch Iranian Med. 2019;22(8):429-34.

\section{Publisher's Note}

Springer Nature remains neutral with regard to jurisdictional claims in published maps and institutional affiliations.

Ready to submit your research? Choose BMC and benefit from:

- fast, convenient online submission

- thorough peer review by experienced researchers in your field

- rapid publication on acceptance

- support for research data, including large and complex data types

- gold Open Access which fosters wider collaboration and increased citations

- maximum visibility for your research: over $100 \mathrm{M}$ website views per year

At BMC, research is always in progress.

Learn more biomedcentral.com/submissions 